\title{
External Validation and Update of a Prediction Rule for the Duration of Sickness Absence Due to Common Mental Disorders
}

\author{
Giny Norder ${ }^{1,2}$ - Corné A. M. Roelen ${ }^{1,2}$ Jac J. L. van der Klink ${ }^{3}$. \\ Ute Bültmann $^{1} \cdot$ J. K. Sluiter ${ }^{4}$ K. Nieuwenhuijsen ${ }^{4}$
}

Published online: 3 June 2016

(C) The Author(s) 2016. This article is published with open access at Springerlink.com

\begin{abstract}
Purpose The objective of the present study was to validate an existing prediction rule (including age, education, depressive/anxiety symptoms, and recovery expectations) for predictions of the duration of sickness absence due to common mental disorders (CMDs) and investigate the added value of work-related factors. Methods A prospective cohort study including 596 employees who reported sick with CMDs in the period from September 2013 to April 2014. Work-related factors were measured at baseline with the Questionnaire on the Experience and Evaluation of Work. During 1-year follow-up, sickness absence data were retrieved from an occupational health register. The outcome variables of the study were sickness absence (no $=0$, yes $=1$ ) at 3 and 6 months after reporting sick with CMDs. Discrimination between workers with and without sickness absence was investigated at 3 and 6 months with the area under the receiver operating characteristic curve (AUC). Results A total of 220 (37\%) employees agreed to participate and 211 (35\%) had complete data for analysis. Discrimination was poor with AUC $=0.69$ and $\mathrm{AUC}=0.55$ at 3 and 6 months,
\end{abstract}

Giny Norder

giny.norder@arboned.nl

1 ArboNed Occupational Health Service, PO Box 85091, 3508 AB Utrecht, The Netherlands

2 Department of Health Sciences, University Medical Center Groningen, University of Groningen, Groningen, The Netherlands

3 School of Social and Behavioral Sciences, Tilburg University, Tilburg, The Netherlands

4 Coronel Institute of Occupational Health, Academic Medical Center, University of Amsterdam, Amsterdam, The Netherlands respectively. When 'variety in work' was added as predictor variable, discrimination between employees with and without CMD sickness absence improved to $\mathrm{AUC}=0.74 \quad$ (at 3 months) and $\mathrm{AUC}=0.62 \quad$ (at 6 months). Conclusions The original prediction rule poorly predicted CMD sickness absence duration. After adding 'variety in work', the prediction rule discriminated between employees with and without CMD sickness absence 3 months after reporting sick. This new prediction rule remains to be validated in other populations.

Keywords Mental disorders - Prognosis - Return to work · Sick leave $\cdot$ Validation studies

\section{Introduction}

Common mental disorders (CMDs) are an increasing burden of disease in the working population and a major cause of long-term sickness absence and disability pensioning [1-7]. In a systematic review, Blank et al. [8] found that only $50 \%$ of the employees absent from work due to CMDs for 6 months or longer returned to work. The other half fails to resume work and ends up receiving a disability pension. If health care providers could use prognostic models and rules to identify employees at risk of long-term CMD sickness absence, then high-risk employees could be referred to treatment or targeted interventions soon after reporting sick. Such a tertiary preventive approach might improve the return to work prognosis.

Earlier, Nieuwenhuijsen et al. (2006) developed a prediction rule for CMD sickness absence duration. Employees aged $>50$ years, with a high educational level, who expected to be off work $>3$ months, and presented with depressive and/or anxiety symptoms were at risk of longer 
duration CMD sickness absence. Receiver Operating Characteristic (ROC) analysis showed that the prediction rule poorly discriminated between employees with and without sickness absence 3 months after reporting sick, with area under the ROC-curve (AUC) 0.68 ; discrimination was fair for employees with and without sickness absence 6 and 12 months after reporting sick, with AUC 0.71 and 0.73 , respectively [9].

The prediction rule was developed in a rather homogeneous sample of 188 Dutch employees (54\% teachers). Prediction rules are practically useful only if they provide accurate risk predictions in different settings. The more heterogeneous the workplace settings in which the prediction rule is tested and found accurate, the more likely it will apply to untested settings [10]. Therefore, the aim of this study was to validate the rule predicting CMD sickness absence duration in a heterogeneous working population. In addition, we investigated the added value of work-related predictor variables to the original prediction rule for CMD sickness absence duration.

\section{Methods}

\section{Study Design and Sample Size}

The study was designed as a cohort study including employees working in companies with a sickness absence insurance and who reported sick with CMDs in the period September 2013 to April 2014. Predictor variables and work-related factors were measured at inclusion. Sickness absence data were retrieved from an occupational health register during 1-year follow-up. The Medical Ethics Committee of the University Medical Center Groningen approved the study (reference METc2011.204).

To calculate the sample size, we used a conservative estimate of 15 outcome events per variable as criterion [11]. As the prediction rule included 4 variables, we needed 60 employees still absent from work at 3, 6, and 12 months after reporting sick. A Dutch study showed that $53 \%$ of the employees who reported sick with CMDs were still sicklisted at 3 months, $30 \%$ at 6 months, and $13 \%$ at 12 months after reporting sick, respectively [12]. Based on these percentages, we estimated that $\mathrm{N}=100, \mathrm{~N}=200$ and $\mathrm{N}=450$ would have to be included to validate the prediction rule for CMD sickness absence at 3, 6, and 12 months, respectively.

\section{Data Collection}

Employees who reported mental problems as cause of sickness absence in the period September 2013 to April 2014 were invited by e-mail to participate in the study.
Those who agreed to participate received an online questionnaire measuring the established predictor variables and work-related factors. In The Netherlands, sickness absence is compensated when medically certified by an occupational physician (OP). OPs certify sickness absence with a diagnostic code based on the 10th version of the International Classification of Diseases (ICD-10). Of the employees who reported sick with mental problems, only those suffering CMDs were included in the analyses. CMD sickness absence was defined as OP-certified within ICD10 diagnostic categories R45 (emotional disturbances), F30-39 (mood disorders), or F40-49 (neurotic disorders). Employees with other mental problems, OP-certified as schizophrenia (F20-29), personality disorders (F60-69), mental retardation (F70-79), and disorders of psychological development (F80-89) were excluded from the analyses, because these diagnoses were not considered CMDs [9]. Employees who were unable to understand or complete an online Dutch questionnaire were also excluded from the analyses.

\section{Outcome Variable}

CMD sickness absence was recorded in an occupational health service register from the day of reporting sick to the day of full return to work (i.e. working the same number of hours per week as before CMD sickness absence). Based on the duration of CMD sickness absence, we defined three outcome variables: sickness absence $($ no $=0$, yes $=1)$ at 3 months, 6 months, and 12 months after reporting sick with CMDs.

\section{Predictor Variables}

The predictor variables age $(\leq 50$ years $=0$; $>50$ years $=1$ ), educational level (low i.e., primary education and junior secondary vocational or general education $=0$; high i.e. senior secondary vocational or general education, higher professional education, and university $=1)$ and recovery expectations $(\leq 3$ months $=0$; $>3$ months $=1)$ were defined according to the development study [9].

Depressive and anxiety symptoms were measured with the Four-Dimensional Symptom Questionnaire (4DSQ), which has shown good psychometric properties in the working population [13, 14]. All 4DSQ items were scored on a 5-point response scale using categories 'no' $(=0)$, 'sometimes' (=1), 'regularly' (=2), 'often' $(=2)$, and 'very often' (=2). The depression scale consists of 6 items (Cronbach's $\alpha=0.91$ ) with a score range $0-12$; scores $\leq 2$ were interpreted as absence of depressive symptoms and scores $>2$ as presence of depressive symptoms [14]. The anxiety scale consists of 12 items $(\alpha=0.89)$ with a score 
range $0-24$; scores $\leq 8$ represented absence and scores $>8$ presence of anxiety symptoms [14]. Dichotomized (i.e., absent $=0$, present $=1$ ) depressive and anxiety scores were summed; a sum score $=0$ was interpreted as absence of depressive and anxiety symptoms and scores 1 and 2 as presence of depressive and/or anxiety symptoms.

\section{Work-Related Factors}

Psychosocial work characteristics were measured with the Questionnaire on the Experience and Evaluation of Work (QEEW) [15, 16]. We used the QEEW scales quantitative demands (11 items; $\alpha=0.92$ ), emotional demands (7 items, $\alpha=0.78$ ), 'variety in work' (6 items, $\alpha=0.88$ ), autonomy in work (11 items, $\alpha=0.91$ ), control over work (8 items, $\alpha=0.88$ ), and support from co-workers (9 items, $\alpha=0.83$ ) and supervisor (10 items, $\alpha=0.93$ ). Responses on these scales were rated on a four-point frequency scale ranging from "never" (=0) to "always" (=3). The sum scores of each scale were standardized as percentage of the maximum scale score, so that scores ranged from 0 to 100 . In the analyses, each work-related factor was included as continuous variable.

Work-family conflict was investigated with the WorkFamily Interface Scale [17]. Negative work-to-family $(\alpha=0.82)$ and negative family-to-work $(\alpha=0.72)$ spillover were measured by 3 items each with five-point frequency responses ranging from "never" $(=0)$ to "very often" (=4); scores were summed (range 0-12) so that higher sum scores reflecting a more conflicting workfamily interface. Work-to-family and family-to-work spillover were each included in the analyses as continuous variable.

\section{External Validation of the Prediction Rule}

External validation of the prediction rule was done with IBM SPSS Statistics for Windows, version 20 (IBM Corp. Armonk, NY, released 2011). Using the logistic regression coefficients from the study sample of Nieuwenhuijsen et al. [9] we composed three linear predictors (LPs):

- $\quad$ LP1 $=0.129-(0.619 *$ age $)-(0.692 *$ education $)$ $-(1.080 *$ expected recovery $)-(0.949 *$ symptoms $)$ for the risk of being absent at 3 months,

- $\quad$ LP2 $=1.436-(0.760 *$ age $)-(1.047 *$ education $)$ $-(0.936 *$ expected recovery $)-(0.860 *$ symptoms $)-$ for the risk of being absent at 6 months, and

- $\quad$ LP3 $=2.719-(1.044 *$ age $)-(1.154 *$ education $)$ $-(0.953 *$ expected recovery $)-(0.552 *$ symptoms $)$ for the risk of being absent at 12 months.
Mean predicted risks were plotted against observed frequencies of CMD sickness absence in a calibration graph. Calibration (i.e., the accuracy of predicted risks) is perfect if calibration graph intercept $=0$ and slope $=1$. In this study, we considered calibration adequate for nonsignificant (i.e., $P \geq 0.05$ ) tests for calibration intercept and slope; miscalibration was concluded for $P<0.05$ [18].

Discrimination between employees with and without CMD sickness absence 3, 6, and 12 months after reporting sick with CMDs was examined with ROC-curves. The area under the ROC-curve (AUC) is a measure for discrimination. AUC $>0.90$ reflects perfect, 0.80-0.89 good, 0.70-0.79 fair, and 0.60-0.69 poor discrimination; $\mathrm{AUC}=0.50$ reflects no discrimination above chance.

\section{Updating of the Prediction Rule}

Until now, we kept the logistic regression coefficients fixed at their original value obtained from the study sample of Nieuwenhuijsen et al. [9]. The prediction rule was re-calibrated by estimating logistic regression coefficients based on the data of the present study population [18]. Then, we added each work variable separately to the re-calibrated prediction rule. Improvement of the prediction rule's ability to discriminate between employees with and without CMD sickness absence was investigated with Integrated Discrimination Improvement (IDI) [19, 20]. IDI $=0$ represents no discrimination improvement after adding the work variable; IDI $>0$ reflects significant discrimination improvement and IDI $<0$ significant worsening of risk discrimination. IDIs were calculated in $\mathrm{R}$ (Project for Statistical Computing) using the predictABEL package [21].

\section{Results}

A total of $\mathrm{N}=596$ employees reported sick with CMD in the period September 2013 to April 2014, of whom $\mathrm{N}=220$ (37\%) agreed to participate in the study. Participants were OP-diagnosed with emotional disturbances $(\mathrm{N}=31)$, mood disorders $(\mathrm{N}=22)$, and neurotic disorders $(\mathrm{N}=164)$; three participants were excluded because they were OP-diagnosed within other ICD-10 F-categories. The questionnaire data of another 6 employees could not be linked to the occupational health service register. Consequently, 211 (35\%) participants with complete data were included in the analyses (Table 1). The majority had a high educational level and worked as administrator (20\%), manager $(10 \%)$, healthcare professional $(10 \%)$, consultant $(10 \%)$, project leader and supervisor $(8 \%)$, or teacher (7\%). 
Table 1 Sample characteristics $(\mathrm{N}=211)$

\begin{tabular}{|c|c|c|}
\hline & Mean $\left(\mathrm{SD}^{\mathrm{a}}\right)$ & $\mathrm{n}(\%)$ \\
\hline Age in years & $44.1(11.9)$ & \\
\hline$\leq 50$ years & & $140(67)$ \\
\hline$>50$ years & & $68(32)$ \\
\hline Missing & & $3(1)$ \\
\hline \multicolumn{3}{|l|}{ Gender } \\
\hline Men & & $90(43)$ \\
\hline Women & & $99(47)$ \\
\hline Missing & & $22(10)$ \\
\hline \multicolumn{3}{|l|}{ Educational level } \\
\hline Low & & $14(7)$ \\
\hline High & & $190(90)$ \\
\hline Missing & & $7(3)$ \\
\hline Recovery expectations in months & $3.2(2.7)$ & \\
\hline$\leq 3$ months & & $139(66)$ \\
\hline$>3$ months & & $50(24)$ \\
\hline Missing & & $22(10)$ \\
\hline Depression (range $0-12$ ) & $3.5(3.4)$ & \\
\hline Anxiety (range 0-24) & $6.4(5.8)$ & \\
\hline \multicolumn{3}{|l|}{ Symptoms } \\
\hline No & & $79(37)$ \\
\hline Yes & & $111(53)$ \\
\hline Missing & & $21(10)$ \\
\hline \multicolumn{3}{|l|}{ Work factors (range 0-100) } \\
\hline Quantitative demands & $55.3(19.7)$ & \\
\hline Emotional demands & $33.7(17.3)$ & \\
\hline Variety in work & $56.2(22.2)$ & \\
\hline Autonomy in work & $47.4(19.2)$ & \\
\hline Control over work & $37.3(19.5)$ & \\
\hline Co-worker support & $68.4(15.7)$ & \\
\hline Supervisor support & $64.5(21.5)$ & \\
\hline \multicolumn{3}{|c|}{ Work-home interference (range 3-12) } \\
\hline Work to family spillover & $6.8(2.2)$ & \\
\hline Family to work spillover & $4.7(1.7)$ & \\
\hline
\end{tabular}

${ }^{\text {a }}$ Standard deviation

\section{External Validation of the Prediction Rule}

The participants had a median CMD sickness absence duration of 155 (interquartile range [IQR] 98-244) days. Three months after reporting sick, $\mathrm{N}=122(58 \%)$ participants were still absent from work. Tests of calibration intercept and slope were significant, indicating that the original rule did not accurately predict the risk of being absent 3 months after reporting sick with CMDs (Table 2). Table 2 shows that discrimination between employees with and without CMD sickness absence at 3 months was poor.
Six months after reporting sick with $\mathrm{CMD}, \mathrm{N}=73$ (35\%) participants were still absent from work. The prediction rule did not accurately predict the risk of CMD sickness absence and failed to discriminate between employees with and without CMD sickness absence at 6 months (Table 2). Eighteen (9\%) participants were still absent from work 12 months after reporting sick with CMD. This number was too small to validate the prediction rule for CMD sickness absence at 12 months.

\section{Update of the Prediction Rule}

When the prediction rules were re-calibrated based on study population data, discrimination improved for CMD sickness absence at 3 months (AUC $=0.69 ; 95 \% \mathrm{CI}$ 0.59-0.80), but not for CMD sickness absence at 6 months (AUC $=0.55 ; 95 \%$ CI 0.45-0.65). When the work-related factor 'variety in work' was added to the prediction rule, discrimination improved to AUCs of 0.74 (95\% CI $0.63-0.85)$ and 0.62 (95\% CI 0.52-0.72) for CMD sickness absence at 3 and 6 months, respectively. The other work-related factors did not significantly improve discrimination (Table 3).

Table 4 shows the added value of 'variety in work' differentiated by the items included in the scale. The items 'repetitious work' and 'task variety' improved the discriminative ability of the prediction rule for CMD sickness absence at 3 months. The scale item 'varied work' improved the discriminative ability of the prediction rule for CMD sickness absence at 6 months.

\section{Discussion}

The original prediction rule for identifying employees at risk of long duration CMD sickness absence was externally validated in a heterogeneous working population. The results showed miscalibration (i.e., the prediction rule did not accurately predict the risk of CMD sickness absence durations of 3 and 6 months) and poor discrimination between employees with and without CMD sickness absence 3 and 6 months after reporting sick with CMDs. Discrimination improved when the prediction rule was recalibrated to the present study population and when "variety in work' was added to the prediction rule. The other psychosocial work characteristics and work-family conflicts did not improve discrimination.

Previously, Nieuwenhuijsen et al. (2006) reported AUCs of 0.68 and 0.71 for sickness absence at 3 and 6 months after reporting sick with CMDs. A potential reason for finding poorer discrimination in the present study is that prediction rules generally perform better in development 
Table 2 External validation of the prediction rule in 211 employees

\begin{tabular}{lclcc}
\hline Sickness absent at & $\mathrm{N}(\%)$ & \multicolumn{2}{l}{ Calibration } & Discrimination \\
\cline { 3 - 5 } & & Intercept $\left(\mathrm{SE}^{\mathrm{a}}\right)$ & Slope $\left(\mathrm{SE}^{\mathrm{a}}\right)$ & AUC $(95 \% \mathrm{CI})^{\mathrm{b}}$ \\
\hline 3 months & $122(79)$ & $1.94(0.55)$ & $0.31(0.31)$ & $0.54(0.41 ; 0.65)$ \\
6 months & $73(47)$ & $0.42(0.18)$ & $0.06(0.23)$ & $0.50(0.40 ; 0.61)$ \\
12 months & $18(12)$ & n.a. & n.a. & n.a.
\end{tabular}

n.a. Not analyzed because of small sample size

${ }^{a}$ Standard error

b Area under the receiver operating characteristic curve (95\% confidence interval)
Table 3 Update of the prediction rule with work-related factors

\begin{tabular}{lll}
\hline Work-related factor & $\begin{array}{l}3 \text { months } \\
\text { IDI }(95 \% \mathrm{CI})^{\mathrm{a}}\end{array}$ & $\begin{array}{l}6 \text { months } \\
\text { IDI }(95 \% \mathrm{CI})^{\mathrm{a}}\end{array}$ \\
\hline Quantitative demands & $1.27(-0.52 ; 3.07)$ & $2.33(-0.00 ; 5.00)$ \\
Emotional demands & $0.00(-1.01 ; 0.90)$ & $1.45(-0.01 ; 3.55)$ \\
Variety in work & $4.71(0.61 ; 8.81)^{*}$ & $2.93(0.00 ; 5.77)^{*}$ \\
Autonomy in work & $0.52(-0.84 ; 1.88)$ & $0.44(-0.43 ; 0.13)$ \\
Control over work & $1.02(-0.65 ; 1.68)$ & $1.00(-0.64 ; 2.64)$ \\
Co-worker support & $-0.25(-0.96 ; 0.46)$ & $0.57(-0.27 ; 1.42)$ \\
Supervisor support & $0.65(-0.00 ; 1.38)$ & $1.22(-0.00 ; 2.81)$ \\
Work to family spillover & $0.72(-0.35 ; 1.78)$ & $0.00(-0.35 ; 0.49)$ \\
Family to work spillover & $0.68(-0.90 ; 2.26)$ & $0.27(-0.31 ; 0.85)$ \\
\hline
\end{tabular}

* Indicates discrimination improvement significant at the $5 \%$ level

${ }^{a}$ Integrated Discrimination Improvement (95\% confidence interval)

than in validation samples [18]. This phenomenon, known as over-optimism, can be problematic when prediction rules are fitted to the data of relatively small development samples. Nieuwenhuijsen et al. [9] corrected for over-optimism by internal validation, fitting the prediction rule to the original data as well as to each of 1000 bootstrap samples. Bootstrapping is a powerful approach to correct for over-optimism and, therefore, it is not likely that the poorer discrimination found in the present study can be explained by over-optimistic performance of the prediction rule in the development study.

The poor discrimination found in the present study might be due to differences between the study populations. When validating a prediction model, researchers should consider the relatedness between the development and validation samples [22]. The development sample comprised employees $(40 \%$ men and $30 \%$ aged $>50$ years) with diverse occupations, but teachers constituted a relatively large proportion (54\%) of the sample.

Our current study population (42\% men and $32 \%$ aged $>50$ years) only included $7 \%$ teachers and may therefore differ too much from the development sample. When recalibrated to the data of the present study population, discrimination by the prediction rule for sickness absence 3 months after reporting sick with CMDs was similar to that reported by Nieuwenhuijsen et al. [9].

An alternative explanation for the different results might be sought in how CMDs were diagnosed. In the development study, Nieuwenhuijsen et al. performed a Composite International Diagnostic Interview (CIDI), diagnosing $36 \%$ of the employees with depressive or anxiety disorders. In the present study, $58 \%$ of the participants presented with depressive or anxiety symptoms as measured with the 4DSQ. This difference could be indicative of diagnostic misclassification or represent a real case-mix difference in the sense that our study included more severe

Table 4 Update the prediction rule with variety in work items

\begin{tabular}{llr}
\hline Variety in work items & $\begin{array}{l}3 \text { months } \\
\text { IDI }(95 \% \text { CI })^{\mathrm{a}}\end{array}$ & $\begin{array}{l}6 \text { months } \\
\text { IDI (95 \% CI) })^{\mathrm{a}}\end{array}$ \\
\hline Do you repeatedly have to do the same things in your work? & $8.27(2.76 ; 13.76)^{*}$ & $0.41(-0.50 ; 1.33)$ \\
Does your work require creativity? & $2.93(-0.59 ; 6.35)$ & $0.19(-0.22 ; 0.59)$ \\
Is your work varied? & $2.11(-0.66 ; 4.89)$ & $2.97(0.00 ; 5.90)^{*}$ \\
Does your work require personal input? & $1.76(-0.69 ; 4.21)$ & $2.60(-0.00 ; 5.23)$ \\
Does your work sufficiently require all your skills and capacities? & $2.07(-0.49 ; 4.63)$ & $2.19(-0.28 ; 4.65)$ \\
Do you have enough variety in your work? & $3.87(0.17 ; 7.56)^{*}$ & $0.64(-0.56 ; 1.84)$ \\
\hline
\end{tabular}

* Indicates discrimination improvement significant at the $5 \%$ level

a Integrated Discrimination Improvement (95\% confidence interval) 
CMDs. Age, gender, OP-diagnoses, and CMD sickness absence duration of study participants were compared with age, gender, OP-diagnoses, and CMD sickness absence duration in 7909 employees of all (i.e., with and without sickness absence insurance) companies, who reported sick with CMDs in the baseline period. The latter were younger (mean age 41.0 years; $t$ test $P<0.01$ ) than the study participants, but did not differ in gender distribution (47\% women; Chi square $P=0.77$ ). They were less often OP-diagnosed with neurotic disorders $(62 \%$, Chi square $P=0.02$ ) and had shorter CMD sickness absence duration (median 107 days, Mann-Whitney $P<0.01)$ than the study participants, which indicates that the present study might have included participants with more severe CMDs.

Another explanation for the poor performance of the prediction rule could be sought in the different time frames. The current study was conducted 9 years after developing the prediction rule. Meanwhile, the treatment and management of CMDs has changed. Therapy now advocates to add work-directed interventions to the treatment of CMDs [23-25]. This may have changed attitudes towards work and recovery expectations of employees with CMDs. In addition, economic and labor market changes in the past 9 years may have affected CMD sickness absence durations, attributing to our different findings.

\section{Study Strengths and Limitations}

The prospective design of the study and the use of registered sickness absence data are assets of the study. A further advantage is that our study included a heterogeneous working population, although the $37 \%$ participation rate restricts the generalizability of results to other populations of employees sick-listed with CMDs. When comparing the study participants with all employees who reported sick with CMDs in the same time frame, we found that our study might have included employees suffering more severe CMDs with longer median sickness absence durations. In addition, companies which have sickness absence insurances are generally small companies staffing up to 100 employees.

Work-related factors were studied by self-administered online questions. Although by far the most widely used way to assess psychosocial work environment characteristics, self-reported measures might be influenced by personal dispositions, mood, expectations, previous experiences, and health [26, 27]. Hence, differential and nondifferential misclassification could not be excluded and might explain why work-related factors did not improve discrimination between worker with and without sickness absence at 3 and 6 months after reporting sick with CMDs.
The finding that work-related factors do not improve discrimination between employees with and without long duration sickness absence is in line with results from previous studies on predictions of high sickness absence days in Norwegian nurses and Danish eldercare workers $[28,29]$. This indicates that, despite being associated with sickness absence duration, psychosocial work characteristics do not discriminate between employees with and without long-term duration sickness absence.

\section{Practical Implications and Directions for Further Research}

The original prediction rule poorly discriminated between employees with and without sickness absence at 3 and 6 months after reporting sick with CMDs. Discrimination improved when the prediction rule was re-calibrated to the data of present study population. When 'variety in work' was added, the re-calibrated prediction rule discriminated between employees with and without sickness absence at 3 months with $\mathrm{AUC}=0.74$. In other words, if we randomly select an employee who is still absent from work at 3 months and an employee who has fully resumed work at 3 months, the prediction rule will correctly assign the highest risk to the employee who is still absent from work in $74 \%$ of the cases. However, re-calibrating the model for the present study population and adding additional variables creates a new prediction rule. Therefore, we still have to test the discriminative performance of the prediction rule in other validation studies of employees sick-listed with CMDs.

For practical use, predictor variables have to be readily available or easy to obtain by healthcare providers. The scale measuring 'variety in work' consists of 6 items, which could be administered during consultations with employees. If further research shows that the prediction rule with 'variety in work' applies to untested settings, then health care providers could use the prediction rule in first consultations with employees sick-listed with CMDs to identify those at risk of long (i.e., $>3$ months) duration CMD sickness absence. This tertiary preventive approach would enable health care providers to decide in an early stage of sickness absence to refer employees to interventions aimed at recovery and return to work [23, 24]. To facilitate its use in occupational healthcare practice, the prediction rule has to be modified into a simpler format and cut-off points have to be determined to decide which employees to refer. Furthermore, it remains to be investigated whether using the prediction rule to early refer highrisk employees to interventions facilitates return to work and improves the return to work prognosis of CMD sickness absence. 


\section{Conclusion}

The original prediction rule poorly discriminated between employees with and without CMD sickness absence at 3 and 6 months after reporting sick. When 'variety in work' was added as predictor variable, the prediction rule became a potential tertiary preventive tool to identify employees at risk of long-term (i.e., $>3$ months) CMD sickness absence and refer them to interventions aimed at recovery and return to work in an early stage of CMD sickness absence.

Open Access This article is distributed under the terms of the Creative Commons Attribution 4.0 International License (http://crea tivecommons.org/licenses/by/4.0/), which permits unrestricted use, distribution, and reproduction in any medium, provided you give appropriate credit to the original author(s) and the source, provide a link to the Creative Commons license, and indicate if changes were made.

\section{References}

1. Organization for Economic Cooperation and Development. Sick on the job? Myths and realities about mental health and work. Paris: OECD Publishing; 2011.

2. Vaez M, Rylander G, Nygren $\AA$, Åsberg M, Alexanderson K. Sickness absence and disability pension in a cohort of employees initially on long-term sick leave due to psychiatric disorders in Sweden. Soc Psychiatry Psychiatr Epidemiol. 2007;42:381-8.

3. Gjesdal S, Ringdal RR, Haug K, Maeland JG. Long-term sickness absence and disability pension with psychiatric disorders: a population-based cohort study. Nord J Pyschiatry. 2008;62: 294-301.

4. Foss L, Gravseth HM, Kristensen P, Claussen B, Mehlum IS, Skyberg K. Risk factors for long-term sickness absence due to mental sickness: a register-based 5-year follow-up from the Oslo Health Study. J Occup Environ Med. 2010;52:698-705.

5. Knudsen AK, Øverland S, Aakvaag HF, Harvey SB, Hotopf M, Mykletun A. Common mental disorders and disability pension award: seven year follow-up of the HUSK study. J Psychosom Res. 2010;69:59-67.

6. Ahola K, Virtanen M, Honkonen T, Isometsä E, Aromaa A, Lönnqvist J. Common mental disorders and subsequent disability: a population-based Health 2000 Study. J Affect Disord. 2011;134:365-72.

7. Knudsen AK, Harvey SB, Mykletun A, Øverland S. Common mental disorders and long-term sickness absence in a general working population. The Hordaland Study. Acta Psychiatr Scand. 2013;127:287-97.

8. Blank L, Peters J, Pickvance S, Wilford J, MacDonald E. A systematic review of the factors that predict return to work for people suffering episodes of poor mental health. J Occup Rehabil. 2008;18:27-34.

9. Nieuwenhuijsen K, Verbeek JH, de Boer AG, Blonk RW, van Dijk FJ. Predicting the duration of sickness absence for patients with common mental disorders in occupational health care. Scand J Work Environ Health. 2006;32:67-74.

10. Justice AC, Covinsky KE, Berlin JA. Assessing the generalizability of prognostic information. Ann Intern Med. 1999;130: 515-24.

11. Harrel FE, Lee KL, Mark DB. Multivariate prognostic models: issues in developing models, evaluating assumptions and adequacy, and measuring and reducing errors. Stat Med. 1996;15:361-87.

12. Roelen CA, Norder G, Koopmans PC, van Rhenen W, van der Klink JJ, Bültmann U. Employees sick-listed with mental disorders: who returns to work and when? J Occup Rehabil. 2012;22:409-17.

13. Terluin B, van Rhenen W, Schaufeli WB, de Haan M. The FourDimensional Symptom Questionnaire (4DSQ): measuring distress and other mental health problems in a working population. Work Stress. 2004;18:187-207.

14. Terluin B, van Marwijk HW, Adèr HJ, de Vet HC, Penninx BW, Hermens WL, et al. The Four-Dimensional Symptom Questionnaire (4DSQ): a validation study of a multidimensional self-report questionnaire to assess distress, depression, anxiety and somatization. BMC Psychiatry. 2006;6:34.

15. van Veldhoven M, de Jonge J, Boersen S, Kompier M, Meijman TF. Specific relations between psychosocial job conditions and job-related stress. Work Stress. 2002;16:207-28.

16. van Veldhoven M. http://www.marcvanveldhoven.com/3013\% 20ENG\%20VBBA\%20Uitgebr.pdf. Accessed 22 Dec 2015.

17. Kinnunen U, Feldt T, Geurts S, Pulkkinen L. Types of workfamily interface: well-being correlates of negative and positive spillover between work and family. Scand J Psychol. 2006;47:149-62.

18. Steyerberg EW, Vickers AJ, Cook NR, Gerds T, Gonen M, Obuchowski M, et al. Assessing the performance of prediction models: a framework for traditional and novel measures. Epidemiology. 2010;21:128-38.

19. Pencina MJ, d'Agostinho RB Sr, d'Agostinho RB Jr, Vasan RS. Evaluating the added predictive ability of a new marker: from area under the ROC curve to reclassification and beyond. Stat Med. 2008;27:157-72.

20. Sundström J, Byberg L, Gedeborg R, Michaëlsson K, Berglund L. Useful tests of usefulness of new risk factors: tools for assessing reclassification and discrimination. Scand J Public Health. 2011;39:439-41.

21. Kundu S, Aulchenko YS, van Duijn CM, Janssens AC. PredictABEL: an $\mathrm{R}$ package for the assessment of risk prediction models. Eur J Epidemiol. 2011;26:261-4.

22. Debray TPA, Vergouwe Y, Koffijberg H, Nieboer D, Steyerberg EW, Moons KGM. A new framework to enhance the interpretation of external validation studies of clinical prediction models. J Clin Epidemiol. 2015;68:279-89.

23. Lagerveld SE, Blonk RWB, Brenninkmeijer V, Wijngaards-de Meij L, Schaufeli WB. Work-focused treatment of common mental disorders and return to work: a comparative outcome study. J Occup Health Psychol. 2012;17:220-34.

24. Karlson B, Jönsson P, Pålsson B, Åbjörnsson G, Malmberg B, Larsson B, et al. Return to work after a workplace-oriented intervention for patients on sick-leave for burnout-a prospective controlled study. BMC Public Health. 2010;10:301.

25. Nieuwenhuijsen K, Faber B, Verbeek JH, Neumeyer-Gromen A, Hees HL, Verhoeven AC, et al. Interventions to improve return to work in depressed people. Cochrane Database Syst Rev. 2014;12:CD006237.

26. Persson R, Kristiansen J. The challenge of assessing the psychosocial work environment: why some self-reports should not be interpreted as environmental exposures. Occup Environ Med. 2012;69:932-3.

27. Rugulies R. Studying the effect of the psychosocial work environment on risk of ill-health: towards a more comprehensive assessment of working conditions. Scand J Work Environ Health. 2013;38:187-92.

28. Roelen CA, Heymans MW, Twisk JWR, van Rhenen W, Pallesen S, Bjorvatn B, Moen BE, Magerøy N. Updating and prospective 
validation of a prognostic model for high sickness absence. Int Arch Occup Environ Health. 2015;188:113-22.

29. Roelen CA, Stapelfeldt CM, Heymans MW, van Rhenen W, Labriola M, Nielsen CV, Bültmann U, Jensen C. Cross-national validation of prognostic models predicting sickness absence and the added value of work environment variables. J Occup Rehabil. 2015;25:279-87. 